\title{
Geolocation Services and Marketing Communication from a Global Point of View
}

\author{
Adam Madleňák ${ }^{1, *}$ \\ ${ }^{1}$ University of Ss. Cyril and Methodius in Trnava, Faculty of Mass Media Communication, \\ Department of Marketing Communication, Námestie J. Herdu 2, 91701 Trnava, Slovakia
}

\begin{abstract}
.
Research background: Electronic communication fundamentally influences social behavior of the society. An unlimited virtual connection to the outside world and the minimal costs needed to reach out to a particular subject cause personal contact to become of marginal importance. The starting point may be, in certain cases, the ability of a mobile device to provide interested parties with relatively accurate geographical data mapping the distribution of objects in space. Therefore, localization of individual participants in the communication process becomes a prerequisite for establishing a contact in the real world. Moreover, localization also serves as a tool for creating highly personalized messages based on a combination of geographical, demographic, psychographic and behavioral characteristics.

Purpose of the article: The aim of the paper is to research the peculiarities associated with the localization of portable electronic devices in the space and the associated efforts to improve the level of personalized communication in line with the right timing of wireless distribution of advertising content to the recipient.

Methods: In order to achieve the stated goal, the author made use of several research methods to research the use of localization technologies in software products supporting social interaction between users of portable electronic devices. In particular, the author used analytical, inductive, deductive and comparative research methods. The paper also contains the results of several scientific studies presenting the latest market trends reflecting on research from abroad.

Findings \& Value added: The paper contributes to the definition of the specifics that characterize the various types of localization technologies which convey information to the target audience within SoLoMo marketing.
\end{abstract}

Keywords: software application; geolocation services; mobile marketing; social media; communication

JEL Classification: $M 15 ; M 31 ; O 33$

*Corresponding author: adam.madlenak@ucm.sk 


\section{Introduction}

The use of modern information and communication technologies, which help to save time and money, significantly contributes to streamlining work in various areas of life. Today, many software applications have a built-in location detection. This increases the scope of tasks an application can carry out, improves the quality of services provided and, last but not least, creates an opportunity for mobile application developers to carry out maintenance or repairs of their products. Privacy tools in mobile phones let users choose the extent of access to stored information. A request for permission to use the mobile phone owner's geolocation data is submitted when the device's software is configured for the first time. This process is characterized by a high degree of individualism given the nature of software and programs. These settings can be changed over time [1]. The person has the right to allow or deny the program to use data identifying person's location in relation to others who have the same software application installed. The program may use data relating to the owner of the device only if he expressly authorized the program to do so [2]. However, the ban on geolocation services has recently resulted in a reduction in the functionality of software applications, which affects the efforts of developers to provide quality products.

\section{Methods}

The aim of the paper is to point out the specifics that characterize the various ways of locating portable electronic devices in space. At the same time, the paper tackles the global trend of integrating localization technologies with social media platforms in an effort to develop interpersonal relationships. The paper also pays increased attention to the possibility of implementing marketing communication activities through the navigation software. In order to tackle the issue in a comprehensive and systematic way, we made use of analysis, induction, deduction and synthesis. At the same time, we tried to critically evaluate not only domestic but also foreign literary sources. As a part of the research, we checked the theoretical knowledge and information against practice. The paper also features own observations based on several years of research within the framework of various scientific projects and grants. Our intention was to look for interrelationships between the published claims. One of the tasks was to logically connect all the important elements related to the selected topic as these served as a bedrock in our formulation of conclusions.

\section{Results and discussions}

\subsection{Conditionality of geolocation services}

Geographic information systems consist of a database - a set of structured data that are collected and processed for the purpose of modeling spatial relationships and their presentation on map data. Individual objects are characterized by different positional, temporal and thematic characteristics, which place the analyzed elements into mutual relations [3]. These subsequently have an impact on the situations that arise as a result of the planning in the context of the acquired knowledge. Attention is also paid to the updating of data stored in the system due to changes that have occurred in the meantime as a result of the variability of the external environment.

For the optimal functioning of the geolocation system, we must not underestimate the importance of several of its components which ensure a comprehensive approach to the issue of identifying the position of a subject in space. However, we must realize that they complement each other and integrate in an effort to commercialize geolocation services in 
everyday life. Due to their strict functional conditionality, we can describe the building of a geographic information system as very demanding and unpredictable in the long run $[4,5]$. With regard to the required hardware, we talk about physical objects that make up a computer and its accessories (type of electronic device). On the other hand, software includes programs that target computer's functionality. Software is intangible in nature and includes e.g. operating systems, device drivers, and various types of application programs that we install on our device [6]. Data in the form of geographical data on the observed subject of research and other descriptive information that approximate its behavior and interaction with the surrounding environment are no less important. These must be suitably supplemented by specific methods/ best practices of data processing in order to achieve the desired result in accordance with the established digital marketing strategy of the customer [7]. The competencies and skills of human resources in the field of information literacy are extremely important, too, whether it is the staff responsible for the development and operation of the information system, including its regular maintenance (programmers, graphic designers, database administrators, IT security specialists, etc.) or software endusers [8]. If we are interested in carrying out all planned activities properly, it is necessary, among other things, to explain to the stakeholders the context in which the wording of the individual tasks was formed. This helps to define the relationships between the participants in more detail, as well as to define a specific area of activity in connection with the criteria that the final product should meet. It is also possible to discuss the conditions necessary for the continuous and trouble-free course of the implemented action, which is a starting point for effective work [9, 10]. Insufficient knowledge of the context affects the nature and quality of information contained in other components of the information system. As a result, these can then be defined and understood in a wrong way.

\subsection{Specifics of locating portable electronic devices in space}

In order to determine the approximate location of an electronic device, websites, computer programs, and other software applications usually use GPS technology, mobile transmitters, Wi-Fi hotspots, and Bluetooth networks.

The accuracy of an object's location using GPS technology depends on the number of satellites orbiting the Earth on well-defined orbits in the visibility zone at an average altitude of $20,000 \mathrm{~km}$. It is now possible to monitor not only the current position of stationary, but also moving objects. The GPS positioning system helps to simplify orientation and coordination in space. The device must be able to process the signal coming from at least three space satellites. However, if we are interested in the height of the analyzed object, we must receive and analyze a signal from at least four satellites [11]. Built-in GPS signal receivers are usually a standard part of modern smartphones (due to the provision of complex geolocation services). The device receives a signal from individual satellites with a navigation message determining the distances between the GPS receiver and visible satellites based on the transmission and reception times of the signal. To avoid anomalies, it is essential that GPS satellites are equipped with an accurate atomic clock. The generally accepted error range is considered to be an interval of 3-10 meters (horizontal plane) for software applications that are intended for the general public. Obstacles having a negative impact on GPS satellite signal reception and reducing the accuracy of localization include walls, ceilings and roofs of buildings, motor vehicles, but also mountain ranges, caves, dense forests, large clouds and the like [12, 13]. Illegal or otherwise questionable applications can jeopardize the correct localization of the mobile device, too. By using programs and applications from non-official stores and unverified websites a user runs a risk of a misalignment of the downloaded program/ app. Therefore, resetting a device to factory settings may be required to get rid of any interference. 
In order to define the most accurate position of the mobile device, it is possible to use other techniques if the GPS signal is being blocked. The Wi-Fi signal is one of those. If location services are enabled on the device, information about the geographical location with respect to the nearest $\mathrm{Wi}-\mathrm{Fi}$ access points is sent on a regular basis [14]. Currently, every new smartphone can create a functional Wi-Fi hotspot. As this is a standard function of mobile operating systems, data obtained from the mobile network operator, for example, after the device is connected to its 4G LTE network, is sufficient. 4G LTE is known for its high-speed internet with a quality signal. Subsequently, we can share the mobile Internet connection with other users of smartphone, tablets, laptops and other electronic devices that support Wi-Fi in a relatively simple way.

It is also possible to record data relating to the location of smartphones in the designated area via mobile communication stations. The phone can recognize the transmitter from which it is receiving a GSM signal and determine its position. For geolocation without GPS, it is customary to use a special application with a database of the surrounding mobile communication towers. However, the overall density of network coverage appears to be a problematic factor [15]. In rural areas, especially in villages that have no or only a minimal number of stations in the immediate vicinity, such measurements could be very inaccurate or even impossible. The situation is opposite in larger cities as these brings reliable results.

In connection with the creation of zones capable of providing certain identification data with the aim of closer localization of research objects, we can also talk about the application of Bluetooth technology in the communication process between several devices. To calculate the data that would reliably approximate the position of the object, special chips with sensors are used, the so-called "beacons" located mainly in buildings such as shopping centers, hospitals or airports, less so in public spaces. This location technology is usually deployed in interior spaces, where many times the GPS signal is weak. Static position of the observed object is crucial in order to achieve a reliable (accurate) result [16]. This, however, is the biggest disadvantage of this technology Recently, Bluetooth-based identification has become the basis of activities falling under the concept of proximity marketing with the intention of implementing localized wireless distribution of advertising content at a pre-selected location [17]. The goal of these efforts is a quite innovative and effective addressing of customers based on his shopping preferences in the store, i.e. by providing personalized benefits in the form of discounts, gifts or special offers. Their content can be operatively changed depending on the location of the mobile device in the given store. A personal approach allows retailers to obtain valuable information about shopping habits and at the same time increase the impact of communication activities and brand loyalty. However, these activities shall not be too intrusive.

\subsection{Geomarketing and social media}

The plan for the global commercialization of services based on the identification of the location of the user of the electronic device is based on passive and active approach. With the passive approach, after the subject grants his consent to the intentional localization, the marketer shall respect privacy settings. With active approach activities are carried out by software. With the passive approach, the owner of a device with a navigation system is perceived as a recipient of specific information transmitted within a limited territory or as a sender of data intended solely for the purpose of ascertaining his current location. The essence of the active approach lies in the increased degree of interactivity - adding posts or information containing or referring to the current location or products consumed. In addition, the active approach involves all the user's initiatives to self-search for information relevant to the environment, usually within a few kilometers (with the help of programmed 
software) [18]. Various ethical issues can affect a subject's decision as to whether to allow a software application to access his location at any time while actively (passively) using it. These issues should draw the public's attention primarily to the fact that geolocation services monitor not only the movement of the mobile device itself but also the movement of its owner. This seems to be a particularly serious problem as nowadays smartphones rarely leave the side of their owners [19]. Due to the careless handling of selected applications, we are relatively easily and unnecessarily exposed to the risk of misuse of recorded data.

The reasons for the use of geolocation services by the general public, which is mostly represented by ordinary owners of consumer electronics, vary. The usual reason is the idea of a benefit that would positively affect person's daily performance and improve their productivity. Location technologies allow users to navigate in space. Thanks to their integration with social media platforms, interpersonal relationships are developing in parallel. Users can share places they visited providing information with a geographical location and additional description expressing personal experience. This is a unique way to interact with friends. Such information may serve as an inspiration to others e.g. when planning a family trip, making plans, discovering cultural events, entertainment, shopping or dining [20]. The willingness to share one's own experience with others through a short comment or review usually ultimately leads to an increase in the value of the offer presented in the digital environment.

On the other hand, advertisers should use geomarketing tools as part of their business strategy if they want to regularly and automatically analyze the data of the target customer group. The related activities include, for example, collection and processing of business data according to the regions as such data points to different levels of purchasing power and different purchasing habits. The result is the segmentation of customers according to predetermined parameters on a data map [21]. Due to the analysis of factors that may affect consumer behavior (with respect to distance to the nearest point of interest shown on the map, range of goods, geographical proximity, size and structure and the like), it is equally important to monitor the availability of business entities offering selected goods. Undoubtedly, the implementation of personalized marketing communication in the form of promotional messages to the public based on available geographical, demographic, psychographic and behavioral data can also be of great benefit.

\subsection{Usage of a software product supporting geolocation services in practice}

In order to find solutions to practical problems regarding the geographical distance between users of a particular digital platform and their social interaction, we will focus on several popular online applications. These often combine navigation software with features of a social network and digital game elements e.g. apps for sharing traffic information - traffic jam information, accidents, closures and other obstacles preventing smooth passing, the position of radars and police patrols which monitor compliance with traffic regulations (speed and driving style, texting and making phone calls while driving, drinking alcohol and the like). A bonus is data describing the approximate price of fuel at nearby petrol stations. Since information are added by users of the app (these should be preferably added by a passenger due to safety reasons), the accuracy of the expected time of delay at a particular point of the journey depends on the number of active users. Alternative detours are also on offer. The visible position of subjects on the map helps to estimate the traffic flow and to adjust the generated results accordingly. The intelligent traffic management system can automatically evaluate usefulness of information with regard to the current situation and recommend the optimal variant. Route planning, in turn, allows users to choose the shortest route according to the average delay in a given hour and day resulting 
from weekly statistics. Thus, users themselves can participate in the creation of new maps through the available software. After marking the type of road and assigning an official name to it, the marked route is expected to become a permanent part of the database accessible to all drivers via mobile devices. However, this requires prior confirmation of the existence of the particular road by other users. The social aspect of navigation is based, among other things, on the ability to respond immediately to all information published by software users. Users can confirm but also refute the reported increased risk at a particular place. If users pass through a marked place, it is possible to comment on the situation and bring more detailed information. Users are also able to leave a private message to other drivers in a traffic jam with detailed information. User groups are a great way to ensure more efficient communication and information sharing. Thanks to the integration of the application with the most famous social media, we can even identify our friends in the area and contact them. Several elements of gamification are intended to make the software more attractive to the public and to encourage interaction [22, 23]. These elements reward users for being online while driving with the program turned on for repeatedly publishing traffic information. The reward is access to various graphic designs modifying the profile of the user visible to everyone on the map. Different profile icons or layouts are rewards for providing traffic information and securing smooth traffic. Users can also brag to other members of the community with the number of points earned for the mileage with the application on, amount of information provided. Despite the fact that drivers are not materially rewarded, their satisfaction is stimulated by the visible ranking compiled by comparing selected categories of activities in a certain area. A great example of a mobile application which includes most of the above-mentioned characteristics is the navigation software known as Waze (see Figure 1), Inrix or Maps.me.


Fig. 1. Graphical user interface of the mobile application Waze

\section{Conclusions}

In an effort to popularize geolocation services, existing location platforms are now often integrated with social media. Users have unrestricted access to these anytime and anywhere, especially through their mobile devices. A completely new standard is emerging regarding the exchange, sharing and downloading content with information value in a digital environment known as the SoLoMo concept (social / local / mobile). It has never been easier to find a way in an unfamiliar setting - geolocation services and the publicly 
published experiences of others make it possible. Developing social interaction and maintaining contacts between people can ultimately lead to the creation of multilateral mutually beneficial relationships. From a long-term perspective, we see a potential for the development of database marketing thanks to the systematic monitoring of stored records and data. For the sake of personalization, proper timing and precise targeting of marketing communication it is necessary to thoroughly examine the preferences and habits of users of software applications.

The paper was drawn up under the VEGA project ",Aspects of using the concept of SoLoMo marketing to increase awareness of eco-innovations", no. 1/0708/18 2018-2020, head researcher prof. Ing. Anna Zaušková, PhD.

\section{References}

1. Procentese, F., Gatti, F. (2019). People-Nearby Applications and Local Communities: Questioning about Individuals' Loneliness and Social Motivations toward PeopleNearby Applications. Journal of Community Psychology, 47(5), 1282-1294.

2. Svec, M., Olsovska, A., Mura, L. (2015). Protection of an "Average Consumer" in the Digital Society - European Context. Marketing Identity: Digital Life - Part II.: Conference Proceedings from International Scientific Conference (pp. 273-282). Trnava: University of Ss. Cyril and Methodius in Trnava.

3. Chang, F. M., Wang, H. L. et al. (2013). The Development of a Mobile Learning System with Provisioning for Location-based Services and Monitoring. Journal of Science and Engineering Technology, 9(1), 67-77.

4. Hsieh, M. (2018). SoLoMo Technology: Exploring the Most Critical Determinants of SoLoMo Technology in the Contemporary Mobile Communication Technology Era. Journal of Ambient Intelligence and Humanized Computing, 9(2), 307-318.

5. Kupec, V. (2017). Digital Possibilities of Internal Audit. Acta VŠFS, 11(1), 28-44.

6. Steinhoff, L. Arli, D., Weaven, S., Kozlenkova, I. V. (2019). Online Relationship Marketing. Journal of the Academy of Marketing Science, 47(3), 369-393.

7. Koraus, A., Kascakova, Z., Felcan, M. (2020). The Impact of Ability-enhancing HRM Practices on Perceived Individual Performance in IT Industry in Slovakia. Central European Journal of Labour Law and Personnel Management, 3(1), 33-45.

8. Olsovska, A., Mura, L., Svec, M. (2016). Personnel Management in Slovakia: An Explanation of the Latent Issues. Polish Journal of Management Studies, 13(2), 110120.

9. Noskova, M., Peracek, T. (2019). Termination of Employment in the Slovak Republic as a Key Issue of HR Management. Central European Journal of Labour Law and Personnel Management, 2(2), 44-59.

10. Mura, L., Gontkovicova, B., Dulova Spisakova, E., Hajduova, Z. (2019). Position of Employee Benefits in Remuneration Structure. Transformations in Business \& Economics, 18(2), 156-173.

11. Rapant, P. (2006). Geoinformatika a geoinformační technologie. Ostrava: Technická univerzita Ostrava.

12. Liborio, M., Bernardes, P., Ekel, P., Ramalho, F. D., dos Santos, A.C.G. (2020). Geomarketing and the Locational Problem Question in the Marketing Studies. Revista Brasileira de Marketing, 19(2), 448-469. 
13. Werner, M. (2014). Indoor Location-Based Services: Prerequisites and Foundations. Cham: Springer.

14. Hua, H. (2019). Mobile Marketing Management: Case Studies from Successful Practices. New York: Routledge.

15. Kneidinger-Mueller, B. (2019). When the Smartphone Goes Offline: A Factorial Survey of Smartphone Users' Experiences of Mobile Unavailability. Computers in Human Behavior, 98, 1-10.

16. Mueller, J., Pommeranz B., Weisser, J., Voigt, K.I. (2018). Digital, Social Media and Mobile Marketing in Industrial Buying: Still in Need of Customer Segmentation? Empirical Evidence from Poland and Germany. Industrial Marketing Management, 73, 70-83.

17. Swart, J., Peters, Ch., Broersma, M. (2019). Sharing and Discussing News in Private Social Media Groups. The Social Function of News and Current Affairs in LocationBased, Work-Oriented and Leisure-Focused Communities. Digital Journalism, 7(2), 187-205.

18. Tkhorikov, B., Klimova, T., Gerasimenko, O., Titova, I.N., Ozerova, M.M. (2019). Geomarketing: New Concept or Applied Business Tool? Revista Inclusiones, 6, 371384.

19. Poor, J., Engle, A. D., Kovacs, A., Albrychiewicz-Slocinska, A., Caha, Z., Kumpikaite-Valiuniene, V., Horbulak, Z. (2020). Initial Findings for Labour Markets in the Czech Republic, Hungary, Poland and Slovakia. Central European Journal of Labour Law and Personnel Management, 3(1), 46-59.

20. Qiu, L., Shi, Z., Whinston, A. (2018). Learning from Your Friends' Check-Ins: An Empirical Study of Location-Based Social Networks. Information Systems Research, 29(4), 1044-1061.

21. Moura, M., Faria, A. (2019). Production, Search and Information Sharing in the Context of Mobile Commerce. Em Questao, 25(1), 414-441.

22. Schneider, S. (2015). Mobile Marketing - Die Moderne Marketingkommunikation: Die Integration von Mobile Marketing in den Marketing-Mix. Hamburg: Igel Verlag.

23. Seiffert-Brockmann, J., Weitzl, W., Henriks, M. (2018). Stakeholder Engagement through Gamification Effects of User Motivation on Psychological and Behavioral Stakeholder Reactions. Journal of Communication Management, 22(1), 67-78. 